\title{
Thermoecological cost of electricity, heat and cold generated in a trigeneration module fuelled with selected fossil and renewable fuels
}

\author{
Sergio Usón a, Wojciech J. Kostowski ${ }^{\text {b, * }}$, Wojciech Stanek ${ }^{\text {b }}$, Wiesław Gazda ${ }^{\text {b }}$ \\ ${ }^{a}$ Centre of Research for Energy Resources and Consumptions (CIRCE), Department of Mechanical Engineering, Universidad de Zaragoza, Zaragoza, Spain \\ ${ }^{\mathrm{b}}$ Institute of Thermal Technology, Silesian University of Technology, Gliwice, Poland
}

\section{A R T I C L E I N F O}

\section{Article history:}

Received 15 November 2014

Received in revised form

24 April 2015

Accepted 4 May 2015

\section{Keywords:}

Thermoecological cost

Thermoeconomics

Trigeneration

Syngas

CMM (coal mine methane)

Natural gas

\begin{abstract}
A B S T R A C T
The paper presents a thermoecological evaluation of a trigeneration module based on an Internal Combustion Engine fuelled with selected fuels of various origin: domestic/mixed-origin natural gas, CMM (coal mine methane) and biogas. The generated products comprise: electric energy, heat available in hot water and cold generated in an absorption chiller. Transformations of energy and exergy in the trigeneration module have been analysed, and the TEC (thermoecological cost) of the products has been determined. The decomposition of TEC into the cost of resources, the contribution of process irreversibility and the equivalent cost of noxious substances has been shown. The chosen gaseous fuels reflect four different cases: a fossil, non-renewable resource ( 1 - domestic, 2 - mixed origin) 3 - a by-product from the extraction of a fossil resource and $4-$ a renewable resource. It has been demonstrated how the TEC of final products depends on the chosen resource, on the process irreversibility, and on the waste contribution. TEC of electricity produced in the trigeneration module varies from 0.30 (biomass syngas) to 3.11 (mixed origin natural gas), and the TEC of the generated heat and cold varies from 0.61 to 6.46 (heat) and 3.37 and 35.5 (cold) accordingly.
\end{abstract}

๑) 2015 Elsevier Ltd. All rights reserved.

\section{Introduction}

Consumption of energy, especially electricity, is the basic factor deciding about the development of humankind civilisation. Many economists maintain that the increase of the consumption is necessary for further economic growth [1,2]. Simultaneously, the growing global consumption of energy and other useful goods accelerates the depletion of non-renewable resources [3]. Sustainable development requires a much more rational management of these resources to provide the next generations with resources they will need to exist. For this reason, two problems are especially important nowadays:

1. development of resource-efficient systems for energy transformations,

2. development of methods for efficient natural resources management.

\footnotetext{
* Corresponding author.

E-mail addresses: suson@unizar.es (S. Usón), wojciech.kostowski@polsl.pl (W.J. Kostowski), wojciech.stanek@polsl.pl (W. Stanek), wieslaw.gazda@polsl.pl (W. Gazda).
}

Two well-known and relevant system solutions for effective energy transformations are cogeneration and trigeneration. Both options ensure a highly efficient utilization of resources, moreover, they can additionally be improved by the introduction of renewable resources or by the application of low-cost fuels obtained as byproducts from many industrial technologies, as demonstrated by numerous recent publications [4-8].

In the case of trigeneration, it is possible to utilize low-grade heat to drive an absorption chiller. Absorption refrigeration chillers have been gaining popularity because they use environmentally friendly working fluids with zero global warming potential e.g. mixture of water-lithium bromide or ammoniawater. In addition, the absorption chillers may be applied with renewable energy sources, such as solar energy $[9,10]$ or waste heat, especially in cogeneration systems [11-13]. The current development concerns the selection of working fluids as refrigerant/absorbent e.g. n-butane/n-octane [14], ionic-liquid/ mixed refrigerant [15]. Also, research is done on combined system configurations, e.g. ejector-double effect absorption refrigeration systems [16], ammonia-water refrigerating system powered by industrial waste heat or a gas turbine exhaust gas [17]. 
The trigeneration system analysed in this paper is based on a commercially available single-effect lithium bromide-water chiller. The main components of a typical single-stage absorption chiller are: a generator, an absorber, a condenser, an evaporator, a solution heat exchanger, a refrigerant pump, a solution pump, and expansion devices $[18,19]$. In the indirect-fired chillers heat is supplied to the generator in the form of hot water, causing the weak absorbent solution to boil. The desorbed refrigerant vapour (in the studied case: water vapour) flows to the condenser, where it is condensed by a flow of cooling water from a cooling tower. The cooling water is also used to cool the strong absorbent solution inside the absorber. The condensed refrigerant enters the evaporator, where the liquid refrigerant boils. In the evaporator, the chilled water cools as it releases the heat required to boil the refrigerant. Apart of the driving heat, absorption chillers also consume a small amount of electricity to drive the refrigerant and solution pumps.

Co- and trigeneration systems produce simultaneously energy carriers of different type. For this reason, their evaluation by means of energy analysis is not enough, and in order to determine their global effectiveness, exergy analysis has to be applied. However, exergy analysis of a system is complex. The local exergy efficiency of a system or component characterises the irreversibility appearing within the assumed boundary but it fails to take into account the interaction between system components. So an important question remains unanswered: how does the exergy cost cumulate along the production process?. This problem can effectively be addressed by the theory of Thermoeconomic Analysis (TE Analysis, TEA) [20-23]. Basing on the concept of Exergy Cost, which is similar to the CExC (Cumulative Exergy Consumption) [24], TE input-output analysis has been developed in order to trace the exergy cost formation process in complex energy conversion systems and to decompose the final product cost according to irreversibility along the productive process. Hence, TEA is a suitable tool for exergetic diagnosis of production systems.

The 'classic' TEA is performed within some assumed boundary of the analysed system and it assumes the unit cost of unity at all system entry points (i.e. all resources entering the system have the exergy cost equal to one). However, from the point of view of natural resources management, the boundary should reach the level of extraction of non-renewable resources from nature. This kind of analysis is possible thanks to the application of the TEC (Thermoecological Cost). According to J. Szargut [25], the TEC is defined as the cumulative consumption of non-renewable exergy connected with the fabrication of a particular product, increased by the additional consumption required to compensate for environmental losses caused by rejection of harmful substances to the environment. For this reason, TEC can be applied as a method of evaluating the sustainability of any production system from the point of view of non-renewable resources management. The dimensionless TEC can be applied as an indicator of sustainability [27]. As demonstrated in Ref. [28], TEC can be applied for both non-renewable and renewable resources; for the latter it is usually less than unity, yet not equal to zero due to various auxiliary costs.

The original mathematical formulation of TEC by Szargut is suitable for relatively simple systems. For more complex cases, like the trigeneration system studied in this paper, it is convenient to integrate both TEA and TEC method. The integration of both methods allows one to analyse how the dimensionless TEC increases through the production system due to irreversibility in its components and due to the emission of harmful substances. This concept was demonstrated by the authors' previous work for a natural gas transport system [29], which was limited to a chosen fossil fuel.
As it was proven in Ref. [28] in order to evaluate the systems fed with a mix of non-renewable and renewable resources, the external evaluation should be done basing on the TEC value. However, the detailed decomposition of cost formation has to be done based on the classic TEA methodology. The aim of this paper is to formulate a new mathematical framework for the integration of the TEA-TEC methods for systems supplied with both non-renewable and renewable external resources. The approach is able to combine advantages of TEC and TEA. Although a preliminary formulation was presented in Ref. [29], in the present paper, it is improved in order to deal with inputs with thermoecological cost lower than unity. Furthermore, its applicability is demonstrated by using an example of a trigeneration system.

The analysed system is based on an ICE (Internal Combustion Engine) fuelled with selected gaseous fuels of various origin: natural gas, CMM (coal mine methane) and syngas obtained from biomass. The generated products comprise: electric energy, heat available in the hot water used for space heating and cold generated in an absorption chiller. The paper trances the transformations of energy and exergy in the system and demonstrates the method of calculating the TEC of products.

\section{Methodology}

The applied methodology comprises: the thermoecological cost, thermoeconomic analysis, and their integration (TEA-TEC).

\subsection{Thermoecological cost}

The TEC proposed by Szargut $[25,26]$ is an evaluation tool applied to measure the efficiency of natural resources management. It combines exergy as a resource's quality indicator and cumulative calculus. TEC of a product fulfilling the rules of exergy cost theory is expressed in units of exergy per unit of product, and is defined as the cumulative consumption of non-renewable natural resources burdening this product, increased by a supplementary term accounting for the necessity to abate or compensate the negative effects of harmful wastes rejection to the natural environment [25,27].

Within this paper, the notation TEC stands for the general term 'thermoecological cost' without specifying the unit (i.e. $\mathrm{kJ} / \mathrm{unit}$ product) while the symbol $r$ is used for the value of the dimensionless TEC $(\mathrm{kJ} / \mathrm{kJ})$.

The value of TEC can be calculated from the balance of cumulative non-renewable exergy consumption. The total value of $\mathrm{TEC}_{j}$ burdening the products of the $j$-th process results first of all from the direct consumption of non-renewable exergy resources supplied to the process. Also, $\mathrm{TEC}_{j}$ results from the consumption of intermediate exergy carriers and/or materials with known TEC index. Additionally, the product of the process $j$ has to be burdened with the TEC resulting from rejection of harmful substances to the environment. If the $j$-th process is a multi-product one, TEC of the main product is decreased by TEC of all byproducts. The detailed description of the balance method with relevant examples is given in Ref. [25]. The balance equations are mutually dependent if some useful product is applied as raw material in another production process. In that case, a system of balance equations should be formulated. In the case of final products for consumption, the balance equations are mutually independent and can be solved by means of a sequence method, beginning with the product and going back through all the production steps. The general form of the balance equation determining the total TEC has been widely presented and discussed in Refs. $[27,30]$. 
In the case of fuels considered in the present study, byproduction does not appear and the TEC balance for $j$-th production branch can be presented in a simplified form:

$T E C_{j}=\sum_{s} \beta_{s j}+\sum_{i} a_{i j} T E C_{i}+\sum_{k} p_{k j} \zeta_{k}$

which can be explained as:

TEC $($ main product $)=$ TEC $($ Direct resources + Input flows + Emissions)

As can be seen in Eq. (1), direct exergy consumption $\beta_{\mathrm{sj}}$, input flows/materials $a_{i j}$ and noxious substances $p_{k j}$ are expressed per unit of product (per $\mathrm{kg}$ or $\mathrm{kJ}$ ). TEC of input flows (materials or exergy flows) supplied to a process depends on the 'history' of given flow. For example, at the extraction field of natural gas, $r=1 \mathrm{~kJ} / \mathrm{kJ}$, since NG (natural gas) flows from underground deposits under its proper pressure. For this reason, the direct consumption of resources $\beta_{s}$ is not multiplied by TEC. On the other hand, the cost of natural gas supplied to consumers is higher due to energy required for its transportation. The last component of Eq. (1) reflects additional expenses of cumulative exergy of non-renewable resources related to the formation of waste products within the $j$-th production process. Determination of the exergy cost of compensation is one of the most complex tasks in the determination of TEC. Szargut [26] proposed a simplified method to determine the TEC of harmful substances based on the information on externalities expressed by monetary indices of harmfulness:

$\zeta_{k}=\frac{B_{r e g} w_{k}}{\mathrm{GDP}-\sum_{k} P_{k, r e g} w_{k}}$

where $B_{\text {reg }}$ is the annual consumption of non-renewable exergy in a given region, $w_{k}$ is the monetary index of harmfulness for the $k$-th substance, GDP is the gross domestic product and $P_{k, \text { reg }}$ is the annual emission of the $k$-th substance in the region. The cost of compensation $\zeta_{k}$ calculated from the external costs $w_{k}$ for main harmful gaseous substances is presented in Table 1 .

In the case of GHG (greenhouse gasses) it is not possible to determine the external cost of losses $w_{k}$. The emissions of GHG (in the considered analysis $\mathrm{CO}_{2}$ and $\mathrm{CH}_{4}$ ) first of all should be expressed as the equivalent $\mathrm{CO}_{2 \mathrm{e}}$ emissions. In the latest IPCC report, the global warming potential of $\mathrm{CH}_{4}$ is estimated at the level of 28 . Additionally it should be noted that the cost of compensation $\zeta_{\mathrm{CO}_{2} \mathrm{e}}$ for carbon dioxide can be calculated based on the cost of abatement by means of sequestration. Detailed methodology is given in Ref. [30].

A particular case is the use of methane from coal mines (CMM), which leads to two main environmental advantages:

1. savings in the primary non-renewable energy e.g. natural gas,

2. decrease of the methane emissions from the coal mine ventilation.

Table 1

Cost of compensation or abatement applied in the TEC balance [31].

\begin{tabular}{lll}
\hline Substance & $\begin{array}{l}\text { Monetary cost } w_{\mathrm{k}}, \\
\text { EUR/kg }\end{array}$ & $\begin{array}{l}\text { Cost of compensation } \\
\zeta_{\mathrm{k}}, \mathrm{kJ} / \mathrm{kg}\end{array}$ \\
\hline $\mathrm{SO}_{\mathrm{x}}$ & 12,81 & 97820 \\
$\mathrm{NO}_{\mathrm{x}}$ & 9,41 & 71880 \\
$\mathrm{Dust}$ & 7,00 & 53420 \\
$\mathrm{CO}$ & $\mathrm{n} / \mathrm{a}$ & $8700^{\mathrm{a}}$ \\
$\mathrm{CO}_{2 \mathrm{e}}$ & $\mathrm{n} / \mathrm{a}$ & $4400^{\mathrm{b}}$ \\
\hline
\end{tabular}

a Evaluated basing on the harmfulness coefficient.
b Expressed as thermoecological cost of abatement.
The latter advantage is related to the fact that during the utilisation, the acquired $\mathrm{CH}_{4}$ is converted to $\mathrm{CO}_{2}$ characterised by the significantly lower GWP index. When the degree of CMM utilisation is lower than one $(\mu<1)$, part of the non-combusted $\mathrm{CH}_{4}$ is released to the environment.

For the calculation of TEC of CMM, the equivalent emission of $\mathrm{CO}_{2 \mathrm{e}}$ has to be introduced to the balance $\mathrm{Eq}(1)$ as follows:

$p_{\mathrm{CO}_{2} e, j}=(1-2 \mu) M_{\mathrm{CH}_{4}} G W P_{\mathrm{CH}_{4}}+\mu M_{\mathrm{CO}_{2}}$

where $M_{\mathrm{CH}_{4}}$ and $M_{\mathrm{CO}_{2}}$ denote molar masses of $\mathrm{CH}_{4}$ and $\mathrm{CO}_{2}$, respectively.

\subsection{Thermoeconomic evaluation}

The aim of the thermoeconomic analysis is the evaluation, optimization and diagnosis of energy intensive systems, and it is based on the combination of exergy (the second law of thermodynamics) and cost (economics) [20,32-35]. The word thermoeconomics was coined by Tribus and Evans [36].

Key concepts in thermoeconomics are fuel and product. The product of a component results from the purpose of its operation, and the fuel is related to resources used to achieve this purpose. For example, in a steam turbine, the decrease of exergy of steam (fuel) is used for producing work (product). In each component $i$ of a system, fuel is always greater than product, and the difference is irreversibility (including loses or external irreversibility):

$F_{i}=P_{i}+I_{i}$

A graphical representation of fuel and product flows for all plant components forms a productive structure of a plant.

Thermoeconomic I-O (input-output) analysis (also named symbolic thermoeconomics) provides a matrix-based method for thermoeconomic analysis. A corresponding detailed formulation can be found in Ref. [37], and only main equations are summarized below.

According to the $\mathrm{I}-\mathrm{O}$ notation, components of the system are numbered from 1 to $n$, and environment is component $0 . E_{i j}$ indicates the part of the product of component $i$ which is part of the fuel of component $j$. Since fuel of a component can come from other components or from the environment, and product of each component is consumed by other components or goes to the environment, it is possible to write:

$F_{j}=\sum_{i=0}^{n} E_{i j}$

$P_{i}=\sum_{j=0}^{n} E_{i j}$

The Fuel-Product table is a table containing elements $E_{i j}$.

Exergy cost of a flow $E_{i j}$ is represented as $E_{i j}^{*}$ and defined as the amount of exergy entering the analysed system needed to produce it [20]. It should be noted that exergy cost does not consider transformation processes located upstream the system, which is a main difference with the TEC. Unit exergy cost is the quotient between exergy cost and exergy, and is denoted by $k^{*}$ :

$k_{i j}^{*}=\frac{E_{i j}^{*}}{E_{i j}}$

Since exergy cost is bound to exergy resources supplied to the system prior to any loses, it is conserved. Besides, exergy decreases due to irreversibility. For this reason, the unit cost $k^{*}$ increases along any real system. 
Symbolic thermoeconomics provides two alternative representations of the system: from fuel to product (FP, used in this paper) or from PF (product back to fuel). FP representation is based on distribution coefficients $y_{j i}$, which indicate how the product of each component is distributed among the other components and the environment:

$y_{j i}=\frac{E_{i j}}{P_{i}}$

If Eq. (9) is combined with Eq. (6), it yields:

$F_{j}=E_{0 j}+\sum_{i=1}^{n} E_{i j}=E_{0 j}+\sum_{i=1}^{n} y_{j i} P_{i}$

Since the cost of the product is distributed proportionally to exergy, an equation similar to Eq. (9) can be written for the cost of flows:

$y_{j i}=\frac{E_{i j}^{*}}{P_{i}^{*}}$

If cost conservation is applied, it can be demonstrated that the vector of exergy cost of the products of all components of the system $\left(\mathbf{P}^{*}\right)$ can be calculated as [37]:

$\boldsymbol{P}^{*}=\left(\boldsymbol{U}_{D}-\langle\boldsymbol{F P}\rangle\right)^{-1} \boldsymbol{F} e$

where $\left\langle\mathbf{F P}>\right.$ is the matrix of elements $y_{j i}, \mathbf{U}_{\mathbf{D}}$ is the identity matrix and $\mathbf{F}_{\mathrm{e}}$ is the vector of external resources (part of fuel coming from the environment).

An alternative to Eq. (12) is:

$\boldsymbol{P}^{*}=\boldsymbol{P}+\left(\boldsymbol{U}_{D}-\langle\boldsymbol{F P}\rangle\right)^{-1} \boldsymbol{I}$

The previous equation shows clearly that exergy cost increase due to irreversibility appearing in the productive process.

It should be noted that unit exergy cost can be obtained by dividing cost into exergy:

$k_{P, i}^{*}=\frac{P_{i}^{*}}{P_{i}}$

\subsection{Integration of thermoecological cost and symbolic thermoeconomics}

In this section, the concept of thermoecological cost is combined with the mathematical formulation of symbolic thermoeconomics in order to obtain a matrix-based formulation of TEC, which is the main contribution of the paper (along with the corresponding demonstration by a case study). A formulation connecting these two concepts was developed in Ref. [29], and it is improved here.

The aim of the proposed formulation is to analyse in detail of how dimensionless thermoecological cost $(r)$ increases due to irreversibility in components and emission of pollutants. The first step is to consider that every exergy flow within the productive structure $\left(E_{i j}\right)$ has its associated flow of TEC $E_{i j}^{*}$,TEC and both are related trough the value of $r$ of that flow:

$r_{i j}=\frac{E_{i j}^{*, T E C}}{E_{i j}}$

The fuel of a component is formed by resources coming either from the environment or from other components (see Eq. (6)). The same happens with the TEC. Thus, the TEC of the fuel of a component is equal to the summation of the flows of TEC entering that component, either from the environment or from other components:

$F_{j}^{*, T E C}=E_{0 j}^{*, T E C}+\sum_{i=1}^{n} E_{i j}^{*, T E C}$

Besides, TEC of the products is distributed proportionally to exergy flows (similarly to exergy in Eq. (9) or exergy cost in Eq. (11)):

$y_{j i}=\frac{E_{i j}^{*, T E C}}{P_{i}^{*}, T E C}$

If Eq. (16) is substituted in Eq. (17), and the result is expressed in the matrix notation, it yields:

$\boldsymbol{F}^{*}, T E C=\boldsymbol{F}_{e}^{*, T E C}+\langle\boldsymbol{F P}\rangle \boldsymbol{P}^{*}, T E C$

Next step is to perform the TEC balance. Since, in every component, TEC of product is equal to TEC of fuel plus TEC of emissions produced in that component, it is possible to write:

$\boldsymbol{P}^{*, T E C}=\boldsymbol{F}^{*, T E C}+\boldsymbol{E M}^{*}, T E C$

where TEC of emissions of component $i$ is calculated as:

$E M_{i}^{* T E C}=\sum_{k} p_{k i} \zeta_{k}$

Where $p_{k i}$ is the amount of emission of pollutant $k$ attributed to component $i$, and $\zeta_{k}$ is the cost of compensation of that pollutant.

If Eqs. (18) and (19) are combined, it yields:

$\boldsymbol{P}^{*}, T E C=\left(\boldsymbol{U}_{D}-\langle\boldsymbol{F P}\rangle\right)^{-1} \boldsymbol{F}_{e}^{*, T E C}+\left(\boldsymbol{U}_{D}-\langle\boldsymbol{F P}\rangle\right)^{-1} \boldsymbol{E M}^{*}, T E C$

The previous equation connects TEC analysis and symbolic thermoeconomics, because it provides the value of the TEC of the product of all components $\left(\mathbf{P}^{*}\right.$,TEC $)$ as a function of the distribution coefficients $\left(y_{j i}\right.$, matrix $\left.<\mathrm{FP}>\right)$, the TEC of external resources entering the system $\left(\mathbf{F}_{e}^{*}\right.$,TEC $)$, and the TEC of emissions $\left(\boldsymbol{E M}^{*}{ }^{*}\right.$ TEC $)$. If TEC of the product of a component $\left(P^{*}, T E C\right)$ is divided into that product $(P)$, the non-dimensional TEC $\left(r_{P}\right)$ is obtained:

$r_{P, i}=\frac{P_{i}^{*}, T E C}{P_{i}}$

If Eq. (21) is transformed, it is possible not only to calculate the value of TEC of the products of all plant components, but also to analyse in detail how this thermoecological cost is formed. A first proposal for this analysis was developed in Ref. [29]. However, this proposal is not suitable for cases where the TEC of the plant fuel is below unity, such as some of the examples analysed here. For this reason, a new decomposition strategy is proposed.

The first step is to introduce the unit TEC of the fuel consumed by the plant $\left(r_{e}\right)$. Thus, the thermoecological cost of plant resources $\left(\mathbf{F}_{e}^{*},{ }^{\text {TEC }}\right)$ is obtained directly by multiplying the value of these resources in exergy $\left(\boldsymbol{F}_{\boldsymbol{e}}\right)$ by their unit TEC $\left(r_{e}\right)$ :

$\boldsymbol{F}_{e}^{*, T E C}=r_{e} \cdot \boldsymbol{F}_{\boldsymbol{e}}$

It should be noted that Eq. (23) is only valid when all inputs to the plant have the same TEC; although it is not a general situation, it is a very common case. 
Besides, if Eqs. (5) and (13) are combined, the following relation can be obtained:

$\boldsymbol{F}_{e}=\left(\boldsymbol{U}_{D}-\langle\boldsymbol{F P}\rangle\right) \boldsymbol{P}+\boldsymbol{I}$

If Eqs. (23) and (24) are combined, it yields:

$\boldsymbol{F}_{e}^{*, T E C}=r_{e} \cdot\left(\boldsymbol{U}_{D}-\langle\boldsymbol{F P}\rangle\right) \boldsymbol{P}+r_{e} \cdot \boldsymbol{I}$

Finally, the TEC decomposition is obtained by substituting Eq. (25) in Eq. (21).

$\boldsymbol{P}^{*}, T E C=r_{e} \cdot \boldsymbol{P}+\left(\boldsymbol{U}_{D}-\langle\boldsymbol{F P}\rangle\right)^{-1}\left(r_{e} \cdot \boldsymbol{I}\right)+\left(\boldsymbol{U}_{D}-\langle\boldsymbol{F P}\rangle\right)^{-1} \boldsymbol{E M}^{*}, T E C$

The previous equation indicates how the TEC of the products of plant components $\left(\boldsymbol{P}^{*} T E C\right)$ is formed throughout the system. The first tem of the right hand side of the equation corresponds to an ideal system with neither irreversibility nor production of pollutants: in this ideal system, TEC of products of all components would be equal to their exergy multiplied by the unit TEC of the plant fuel. The second term is related to irreversibility appearing in all components of the system (I), and the third term corresponds to the additional TEC due to pollutants emitted by all components of the system $\left(\boldsymbol{E M}^{*}\right.$ TEC $)$.

According to the previously presented equations, the value of the unit TEC of the products of all plant components $\left(r_{P}\right)$ and their decomposition considering irreversibility of components and emissions, can be obtained by the following steps:

1. Calculate the exergy of system flows.

2. Obtain the unit TEC of plant fuel $\left(r_{e}\right)$.

3. Determine the TEC of components emissions $\left(\boldsymbol{E M}^{*}, T E C\right)$, by using data of emissions, cost of compensation, and Eq. (20).

4. Define the productive structure of the plant and the fuelproduct table.

5. With the fuel-product table, calculate coefficients $y$ (matrix $<F P>$ ) using Eq. (9).

6. Identify, in the fuel-product table, the product $(P)$ and the fuel $(F)$ of all components.

7. Calculate irreversibility of all components by applying Eq. (5)

8. Apply Eq. (26) for calculating the TEC of the products of all components $\left(\boldsymbol{P}^{*}, T E C\right)$ as well as its decomposition.

9. Calculate the unit TEC of the products of all components $\left(r_{P}\right)$, as well as its decomposition, by using the results of step 8 and Eq. (22).

\section{Case study system description}

The objective of the case study is to provide a realistic energy and exergy balance of a trigeneration system. Since the objective of the paper is to provide an overall thermoeconomic and thermoecological evaluation of the system in terms of the applied fuel, the proposed case study system is a simplified structure operating at nominal parameters, yet correctly representing the transformations of energy and exergy in subsequent devices. Operational problems like part-load characteristics, non-steady operation with heat storage, temporal distribution of demand and control strategies etc. are not discussed.

A scheme of the model trigeneration system is shown in Fig. 1. The system is based on an internal combustion engine (ICE, device 1). The engine consumes gaseous fuel (flux 1) and uses ambient air (flux 2) for combustion. Usable products of the engine comprise: electricity (net output: flux 3 and the power used for driving pumps: fluxes 20-24), and heat (jacket water heated from state 12 to state 6 ). Heat production is extended by the heat recovery heat exchanger (HRHE, device 2 ), where heat is transferred from ICE exhaust gases to the primary water circuit. It can be seen that the entire CHP module is represented by the sum of devices 1 and 2.

Once the heat generated in the ICE and HRHE is joint (junction of fluxes 6 and 7), it is then transferred to the secondary circuit by means of the heat exchanger (PSHE, 3). It is assumed that the temperature level of the 2 nd circuit is $85 / 65^{\circ} \mathrm{C}$. Heat available in this circuit is partially consumed by heat consumers (HC 4 and the flux 25), and partially used to drive an absorption chiller (AC 6). Since the absorption chiller requires barely $5 \mathrm{~K}$ temperature difference of the driving agent, it was proposed to arrange the secondary circuit in series. Hence, the temperature of fluxes 13,14 and 15 are 85,80 and $65^{\circ} \mathrm{C}$, respectively. This assumption entails that the share of heat used to drive the absorption chiller is at the level of about $1 / 4$ of the total, while $3 / 4$ are supplied to heat consumers.

Heat (in the form of hot water) driving the absorption chiller is supplied to the AC generator enabling the refrigeration agent to evaporate and leave the internal absorption cycle. As a result of the cycle, water is cooled from state $19\left(12{ }^{\circ} \mathrm{C}\right)$ to state $17\left(7{ }^{\circ} \mathrm{C}\right)$; this water is then used for cooling purposes. Waste heat produced by the absorption chiller (cycle condenser and the absorber cooling) is rejected by means of warm water $\left(35 / 29{ }^{\circ} \mathrm{C}\right)$ and dissipated in a cooling tower as low-grade heat (flux 27). Electricity consumption of the absorption chiller is due to the $\mathrm{LiBr} / \mathrm{H}_{2} \mathrm{O}$ solution pumps (24) as well as to the pump of the heat rejection water cycle (23).

Since the heat rejected from the absorption chiller cannot be treated as a usable product, it was decided to incorporate the heat rejection cycle and the cooling tower into the symbolic 'Absorption Chiller' device No. 6. Hence, the only usable product of this device is the generated cooling capacity.

The operation of the case study system was modelled for 3 types of gaseous fuel, as listed in Table 3.

Conventional steady-state mass balances (involving stoichiometry) and energy balances were resolved to obtain energy and exergy fluxes related to particular fluxes and devices. Following assumptions and simplifications were applied:

1. The IC engine corresponds to the natural-gas fuelled model Horus HE-EC-1166/1303-MTG1166-GZ rated at $N_{\mathrm{el}}=1166 \mathrm{~kW}$ electric and $Q=1303 \mathrm{~kW}$ thermal (of which $Q_{j w}=660 \mathrm{~kW}$ jacket water and $Q_{H R}=643 \mathrm{~kW}$ exhaust heat recovery to $120^{\circ} \mathrm{C}$ ) [41]. The engine data also comprise: consumption of chemical energy of fuel $N_{\mathrm{ch}}=2822 \mathrm{~kW}$, flux of fuel of $295 \mathrm{~m}^{3} \mathrm{n} / \mathrm{h}$, flux of air of $4638 \mathrm{~m}^{3} \mathrm{n} / \mathrm{h}$; the calculated air excess ratio $\lambda=1.711$.

2. Values of $N_{\mathrm{el}}, Q, Q_{j w}, Q_{H R}, N_{\mathrm{ch}}$ and $\lambda$ are kept constant for all cases (all fuels). As a result, fluxes of air, fuel, exhaust gases and the outlet temperature of exhaust gases leaving the HRHE are variable.

3. The absorption chiller correspond to the model Ebara RCH 013 , with the cooling capacity of $229 \mathrm{~kW}$, heat requirement of $328 \mathrm{~kW}$ and electricity consumption for pumps of $0.95 \mathrm{~kW}$ [42]. The model does not vary between the studied cases.

4. Pressure drops were assumed at the level of $50 \mathrm{kPa}$ per heat exchanger, with the exception of exchangers where the pressure drop is given by catalogue data:

a. refrigeration water, pressure drop across the $A C=76.5 \mathrm{kPa}$ (assumed $75 \mathrm{kPa}$ )

b. heat rejection water, pressure drop across the $\mathrm{AC}=63.7 \mathrm{kPa}$ (assumed $65 \mathrm{kPa}$ )

c. 2nd circuit, pressure drop across the $\mathrm{AC}=131.4 \mathrm{kPa}$ (assumed $130 \mathrm{kPa})$.

5. Heat losses from heat exchangers are neglected.

6. Fuel and air used for combustion are assumed to be at $25{ }^{\circ} \mathrm{C}$ which is the reference temperature for LHV, so that their physical enthalpy can be neglected. 


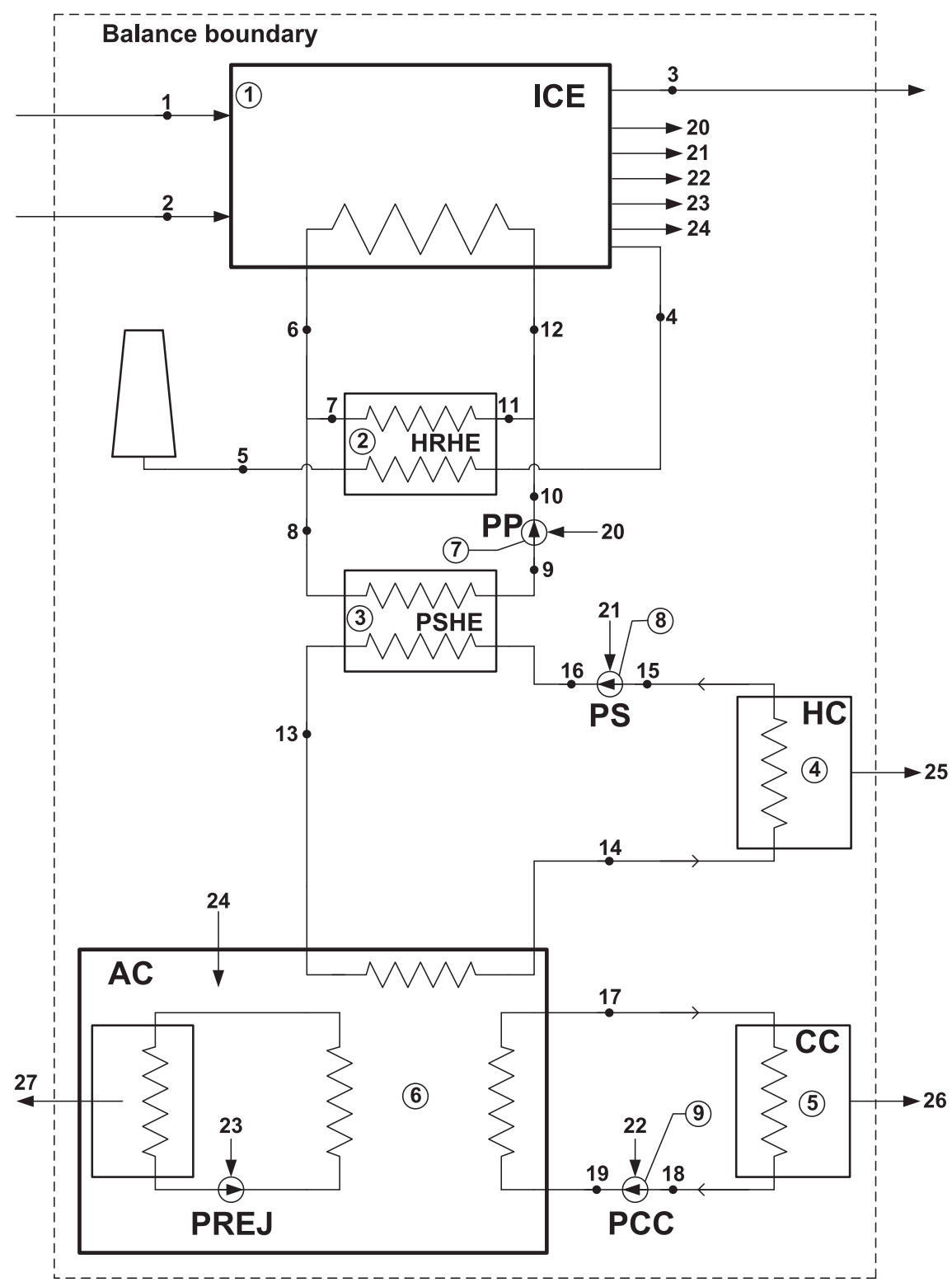

Fig. 1. Technical structure of the proposed trigeneration model system, with enumeration of devices and fluxes. Explication of symbols are given in Table 2 .

7. Reference environment for exergy was assumed at the level of $15{ }^{\circ} \mathrm{C}$ and $100 \mathrm{kPa}$.

Exergy of flows $(\mathrm{kJ} / \mathrm{s})$ was calculated as follows:

a. flowing thermodynamic media:

$\dot{B}_{i}=\dot{m}_{i}\left[h_{i}-h_{0}-T_{0}\left(s_{i}-s_{0}\right)\right]$

b. heat exchanged:

$\dot{B}_{i}=\dot{Q}_{i} \frac{T_{i}-T_{0}}{T_{i}}$

where $\dot{Q}_{i}$ is the $\mathrm{i}$-th heat flux transferred at the mean temperature $T_{i}$.

c. chemical exergy of fuels was calculated after Szargut's results for natural gas [26]:

$\dot{B}=\alpha \dot{V}_{n, i} L H V_{i}, \quad \alpha=1.04$

d. exergy of mechanical/electric energy equals to that energy.
Enthalpy and entropy of fluxes was determined from the library of Engineering Equation Solver V9.503-3D. This software was also used to solve the balance equations for the system.

\section{Results and discussion}

\subsection{Overview of system results}

Results of the mass and energy balance are shown in Table 4. Due to the assumptions made, fluxes from 6 to 27 are the same for all cases. Case-dependent data for the first 5 fluxes are shown in 3-row arrangement and are marked with different text format (NG/SNG/CMM).

It can be observed that the assumption of constant ICE output and constant chemical energy of fuel results in an approximately constant flux of exhaust gases in spite of a strongly variable flux of fuel. Following the transfer of heat to subsequent components of the system, its exergy value is degraded. It is interesting to note that the exergy of the generated cooling agent is extremely low, even 
Table 2

Devices and fluxes of the model system.

\begin{tabular}{lll}
\hline ID & Description & Acronym/parameters \\
\hline A Symbolic devices & \\
1 & Internal combustion engine & ICE \\
2 & Heat recovery heat exchanger & HRHE \\
3 & Primary-secondary circuit Heat Exchanger & PSHE \\
4 & Heat consumer & HC \\
5 & Cool consumers & $\mathrm{CC}$ \\
6 & Absorption chiller & $\mathrm{AC}$ \\
7 & Pump of the primary circuit & $\mathrm{PP}$ \\
8 & Pump of the secondary circuit & $\mathrm{PS}$ \\
9 & Pump of the cooling circuit & $\mathrm{PCC}$ \\
B Fluxes & & \\
1 & Fuel & $25{ }^{\circ} \mathrm{C}$ \\
2 & Air & $25{ }^{\circ} \mathrm{C}$ \\
3 & Net power output & \\
$4-5$ & Exhaust gas & $90 / 70{ }^{\circ} \mathrm{C}$ \\
$6-12$ & Hot water (primary circuit) & $85 / 80 / 65{ }^{\circ} \mathrm{C}$ \\
$13-16$ & Hot water (secondary circuit) & $7 / 12{ }^{\circ} \mathrm{C}$ \\
$17-19$ & Cold water (refrigeration circuit) & \\
$20-24$ & Electricity driving the pumps & \\
25 & Usable heat & \\
26 & Cooling capacity & \\
27 & Heat rejection & \\
\hline
\end{tabular}

Fluxes and devices of the heat rejection circuitary incorporated into the AC, and are not numbered.

Table 3

Fuels applied in the case study trigeneration system - molar composition, \% [38-40].

\begin{tabular}{lccr}
\hline Component/parameter & NG (natural gas) & SNG (syngas) & CMM \\
\hline $\mathrm{CH}_{4}$ & 96.5 & 79.8 & 60.0 \\
$\mathrm{C}_{2} \mathrm{H}_{6}$ & 1.3 & & \\
$\mathrm{C}_{3} \mathrm{H}_{8}$ & 0.3 & & \\
$\mathrm{C}_{4} \mathrm{H}_{10}{ }^{a}$ & 0.1 & & \\
$\mathrm{C}_{5} \mathrm{H}_{10}{ }^{a}$ & 0.02 & & \\
$\mathrm{C}_{6} \mathrm{H}_{12}$ & 0.01 & 11.4 & \\
$\mathrm{H}_{2}$ & & 0.5 & \\
$\mathrm{CO}$ & & 6.0 & 2.0 \\
$\mathrm{CO}_{2}$ & 1.62 & 2.3 & 33.0 \\
$\mathrm{~N}_{2}$ & & & 5.0 \\
$\mathrm{O}_{2}$ & 100.0 & 100.0 & 100.0 \\
Total: & 35902 & 29210 & 21505 \\
LHV, $\mathrm{kJ} / \mathrm{m}^{3}$ & & & \\
\hline
\end{tabular}

a All isomers.

it is lower than the exergy of heat rejected from the absorption chiller.

\subsection{Fuel/product specification}

Fig. 2 illustrates the flows of exergy between system components according to the concept of fuel and product. In a heat exchanger, the decrease of exergy of the hot agent is the symbolic fuel, while the increase of exergy of the cold agent is the symbolic product of the component.

The fuel-product table of the thermoeconomic model as function of the exergy flows of the physical structure appears in Table 5. Each row of the table indicates how the product of a component is distributed to the other components and to the environment, whereas each column shows the origin of the fuel of a component. For instance, the ICE engine (component 1 ) consumes fuel $\left(\mathrm{B}_{1}\right)$ and air $\left(B_{2}\right)$ from the environment $(0)$ and produces: i) electricity to the environment (flow $B_{3}$ ), ii) electricity for pumps (components 7 to 9 and flows $B_{20}$ to $B_{22}$ ) iii) hot exhaust gases to heat exchanger 2 (flow $\mathrm{B}_{4}$ minus flow $\mathrm{B}_{5}$ ) and iv) hot cooling water to heat exchanger 3 (flows $B_{8}$ minus $B_{10}$ ). The total fuel of ICE is $B_{1}+B_{2}$, and its total product is $B_{3}+B_{20}+B_{21}+B_{22}+B_{23}+B_{24}+B_{4}-B_{5}+B_{6}-B_{12}$.
Absorption chiller $(6)$ consumes hot water $\left(B_{13}-B_{14}\right)$ and electricity $\left(B_{23}+B_{24}\right)$ for producing cold water $\left(B_{17}-B_{19}\right)$. It has been considered that the products of pumps 8 and 9 are consumed by components receiving exergy from the circuits (i.e. 4 and 6 , and 5 , respectively). It should be noted that products of heat exchanger 3 and of pump 8 are consumed by components 4 and 6 simultaneously. For this reason, the distribution coefficients $\alpha_{4}$ and $\alpha_{6}$ have been introduced. The calculation of these coefficients is detailed in Eqs. (30) and (31).

$\alpha_{4}=\frac{B_{14}-B_{15}}{B_{13}-B_{15}}$

$\alpha_{6}=\frac{B_{13}-B_{14}}{B_{13}-B_{15}}$

\subsection{Thermoecological cost of input fuels}

TEC of several fuels was calculated according to the methodology explained in Section 2.1. Results are shown in Table 6. Fuels selected for the trigeneration case study are set in bold.

It should be noted that the technical evaluation of the system comprises three types of fuel (CMM, natural gas, SNG). However, TEC of natural gas strongly depends on its origin due to the impact of transportation. Hence, in the thermoecological evaluation, two kinds of natural gas are considered, although their composition is assumed the same for both cases.

\subsection{Thermoecological cost formation}

The methodology presented in Section 2.3 has been applied for the calculation of the thermoecological cost formation of the products of the components of the analysed CHP plant. Four situations have been considered: $i$ ) coal mine methane (1 CMM), ii) domestic natural gas with methane emission(3domNG), iii) Polish mix natural gas with methane emission (7 PmixNG) and iv) SNG from biomass (9 SNGbio).

The process of formation of unit TEC of the products of the nine CHP plant components $\left(r_{P}\right)$ when coal mine methane is used as fuel appears in Table 7. The total values of these TECs appear in the second row (TOTAL $\mathrm{r}_{\mathrm{P}}$ ). It can be seen that the lowest value corresponds to the internal combustion engine (component 1, ICE), which is equal to 0.9082 . This low value is due to the fact that the component is located at the beginning of the productive chain. Unit exergy cost for pumps (components 7, 8 and 9) consuming electricity produced by ICE are slightly higher (0.9328, 0.9440 and 1.0963, respectively). Unit TEC of the products of heat exchangers 2 and 3 are higher. Finally, the product costs for the absorption chiller (6) and heat exchanger (5) increase a lot (around 10).

The other rows of the table quantify the unit TEC formation process for the product of the components: according to Eq. (26), TEC can be de composed as a summation of the TEC that an ideal system with neither irreversibility nor pollutants would have (row IDEAL SYSTEM), plus additional terms due to irreversibility taking place in the different components of the system (rows I1. ICE to I 9, PCC) plus the effect of pollutants generated by the system (rows EM $\mathrm{SO}_{2}$ to EM CO).

The row ideal system reflects the TEC of a system with neither irreversibility nor production of pollutants; in this situation, the unit TEC is equal to that of the fuel ( 0.220 in this example). Rows I 1. ICE to I 9. PCC quantify the impact of irreversibility of different components on the TEC of all components. For instance, irreversibility in component 6 has an impact of 0.997 on the TEC of component 5, and an impact of 0.8843 in the TEC of component 6 . 
Table 4

Mass and energy balance results, exergy of fluxes.

\begin{tabular}{|c|c|c|c|c|c|}
\hline ID & Flux description & Flow, kg/s & Pressure, kPa & Temp., ${ }^{\circ} \mathrm{C}$ & Exergy,kW \\
\hline 1 & Fuel gas & $\begin{array}{l}\mathbf{0 . 0 5 8 4} 0.0694 \\
0.1251\end{array}$ & 115 & 25 & 2935.0 \\
\hline 2 & Air & $\begin{array}{l}\mathbf{1 . 6 6 6} \\
1.646 \\
1.590\end{array}$ & 100 & 25 & 0.3 \\
\hline 3 & Electricity & - & - & - & 1155.0 \\
\hline 4 & Exhaust gas & $\begin{array}{l}\mathbf{1 . 7 1 6} \\
1.707 \\
1.708\end{array}$ & 105 & 453 & $\begin{array}{c}324.2 \\
323.1 \\
322.6\end{array}$ \\
\hline 5 & Exhaust gas & $\begin{array}{l}\mathbf{1 . 7 1 6} \\
1.707 \\
1.708\end{array}$ & 105 & $\begin{array}{l}\mathbf{1 2 0} \\
118.7 \\
118.2\end{array}$ & $\begin{array}{l}\mathbf{3 3 . 4} \\
32.6 \\
32.3\end{array}$ \\
\hline 6 & Primary circuit & 8.20 & 350 & 90 & 288.5 \\
\hline 7 & Primary circuit & 7.35 & 350 & 90 & 258.7 \\
\hline 8 & Primary circuit & 15.55 & 350 & 90 & 547.2 \\
\hline 9 & Primary circuit & 15.55 & 300 & 70 & 306.5 \\
\hline 10 & Primary circuit & 15.55 & 400 & 70 & 308.1 \\
\hline 11 & Primary circuit & 7.35 & 400 & 70 & 145.7 \\
\hline 12 & Primary circuit & 8.20 & 400 & 70 & 162.4 \\
\hline 13 & 2nd circuit & 15.59 & 480 & 85 & 484.5 \\
\hline 14 & 2nd circuit & 15.59 & 350 & 80 & 420.4 \\
\hline 15 & 2nd circuit & 15.59 & 300 & 65 & 256.9 \\
\hline 16 & 2nd circuit & 15.59 & 530 & 65 & 260.5 \\
\hline 17 & Refrigeration water & 10.90 & 350 & 7 & 7.9 \\
\hline 18 & Refrigeration water & 10.90 & 300 & 12 & 2.9 \\
\hline 19 & Refrigeration water & 10.90 & 425 & 12 & 4.3 \\
\hline 20 & Electricity & - & - & - & 1.6 \\
\hline 21 & Electricity & - & - & - & 3.7 \\
\hline 22 & Electricity & - & - & - & 1.6 \\
\hline 23 & Electricity & - & - & - & 2.9 \\
\hline 24 & Electricity & - & - & - & 1.0 \\
\hline 25 & Heat (energy value: 980 kW) & - & - & 72.5 & 163.0 \\
\hline 26 & Cooling (energy value: $227 \mathrm{~kW}$ ) & - & - & 9.5 & 4.4 \\
\hline 27 & Heat rejection (energy value: $557 \mathrm{~kW}$ ) & - & - & 32 & 31.1 \\
\hline
\end{tabular}

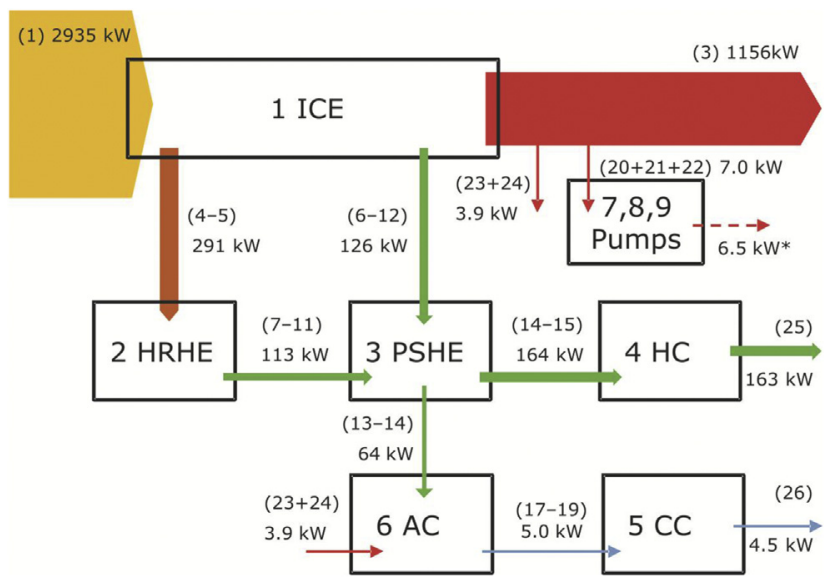

Fig. 2. Exergy flow across the trigeneration system (case: natural gas). The product of pumps 7, 8, 9 (6.5 kW mechanical exergy) is distributed as fuel for all remaining devices, which is not shown in the diagram.

Each component affects the cost of product for components located downstream the productive process (including the cost of its own products), and is affected by the irreversibility of components located upstream (this productive chain is represented graphically in Fig. 2). Since component 1 is located at the beginning, its irreversibility affects all components (all numbers in row I1. ICE are nonzero), but is affected only by its own irreversibility (in the column of I1. ICE), zero appears in all rows from I 2. HRHE to I 9. PCC. On the other hand, component 5 is at the end of the process and its irreversibility affects only the unit TEC of its own product (in the row I 5. CC, the only nonzero element appears in column 5. CC) but is affected by the irreversibility of all components located upstream (in column 5. CC all rows I have nonzero value except I 4. HC). The last four rows represent the contribution of emissions: $\mathrm{EM} \mathrm{SO}_{2}, \mathrm{EM}$ $\mathrm{NO}_{\mathrm{x}}, \mathrm{EM} \mathrm{CO} 2$ and EM CO. In this example, where the TEC of fuel is low, the effect of pollutants is relevant: actually, effect of $\mathrm{CO}_{2}$ emissions accounts for half of the unit TEC of flows.

Unit TEC of the products of components when the system is fed with domestic natural gas (taking into account methane emission) is represented in Table 8. Since the unit TEC of fuel $\left(r_{e}\right)$ is much higher than in the previous example (more than four times), TEC of products increases substantially. This increment is due to the direct effect of fuel (row IDEAL SYSTEM) and also due to irreversibility (rows I 1. ICE to I 9. PCC): although irreversibility (I) is quite similar, it implies the destruction of exergy at a higher cost (thus, having a higher impact), as it can be seen in the second term of right hand side of Eq. (26), where $r_{e}$ appears multiplying $I$. The absolute effect of pollutants is similar to the previous example, except for the case of $\mathrm{SO}_{2}$, which now is nonzero (although the relative contribution of pollutants is smaller due to the aforementioned higher impact of TEC of plant fuel).

Table 9 represents the unit TEC and its formation for the case study system consuming the Polish natural gas mix (also including methane emissions). Since this fuel has the highest thermoecological cost, also the TEC of particular products is very high.

Finally, the unit TEC of system products when syngas from biomass gasification is used appears in Table 10. This fuel has the lowest TEC, which causes also low values for that cost in the products of the system. Furthermore, the effect of $\mathrm{CO}_{2}$ emission can be cancelled because it is equal to that captured by biomass during the growing stage. It should be highlighted that $\mathrm{CO}_{2}$ emissions 
Table 5

Fuel-product table.

\begin{tabular}{|c|c|c|c|c|c|c|c|c|c|c|c|}
\hline & $\mathrm{F}_{0}$ & $\mathrm{~F}_{1}$ & $\mathrm{~F}_{2}$ & $\mathrm{~F}_{3}$ & $\mathrm{~F}_{4}$ & $\mathrm{~F}_{5}$ & $\mathrm{~F}_{6}$ & $\mathrm{~F}_{7}$ & $\mathrm{~F}_{8}$ & $\mathrm{~F}_{9}$ & Total product \\
\hline $\mathrm{P}_{0}$ & 0 & $\mathrm{~B}_{1}+\mathrm{B}_{2}$ & & 0 & 0 & 0 & 0 & 0 & 0 & 0 & $\mathrm{~B}_{1}+\mathrm{B}_{2}$ \\
\hline$P_{1}$ & $\mathrm{~B}_{3}$ & 0 & $\mathrm{~B}_{4}-\mathrm{B}_{5}$ & $\mathrm{~B}_{6}-\mathrm{B}_{12}$ & 0 & 0 & $\mathrm{~B}_{23}+\mathrm{B}_{24}$ & $\mathrm{~B}_{20}$ & $\mathrm{~B}_{21}$ & $\mathrm{~B}_{22}$ & $\begin{array}{l}\mathrm{B}_{3}+\mathrm{B}_{20}+\mathrm{B}_{21}+\mathrm{B}_{22}+\mathrm{B}_{23}+\mathrm{B}_{24}+\mathrm{B}_{4} \\
-\mathrm{B}_{5}+\mathrm{B}_{6}-\mathrm{B}_{12}\end{array}$ \\
\hline $\mathrm{P}_{2}$ & 0 & 0 & 0 & $\mathrm{~B}_{8}-\mathrm{B}_{10}-\mathrm{B}_{6}+\mathrm{B}_{12}$ & 0 & 0 & 0 & 0 & 0 & 0 & $\mathrm{~B}_{8}-\mathrm{B}_{10}-\mathrm{B}_{6}+\mathrm{B}_{12}$ \\
\hline $\mathrm{P}_{3}$ & 0 & 0 & 0 & 0 & $\begin{array}{l}\left(B_{13}-B_{16}\right) \\
\alpha_{4}\end{array}$ & 0 & $\left(B_{13}-B_{16}\right) \cdot \alpha_{6}$ & 0 & 0 & 0 & $\mathrm{~B}_{13}-\mathrm{B}_{16}$ \\
\hline $\mathrm{P}_{4}$ & $\mathrm{~B}_{25}$ & 0 & 0 & 0 & 0 & 0 & 0 & 0 & 0 & 0 & $\mathrm{~B}_{25}$ \\
\hline $\mathrm{P}_{5}$ & $\mathrm{~B}_{26}$ & 0 & 0 & 0 & 0 & 0 & 0 & 0 & 0 & 0 & $\mathrm{~B}_{26}$ \\
\hline $\mathrm{P}_{6}$ & 0 & 0 & 0 & 0 & 0 & $\mathrm{~B}_{17}-\mathrm{B}_{19}$ & 0 & 0 & 0 & 0 & $\mathrm{~B}_{17}-\mathrm{B}_{19}$ \\
\hline $\mathrm{P}_{7}$ & 0 & 0 & 0 & $\mathrm{~B}_{10}-\mathrm{B}_{9}$ & 0 & 0 & 0 & 0 & 0 & 0 & $\mathrm{~B}_{10}-\mathrm{B}_{9}$ \\
\hline $\mathrm{P}_{8}$ & 0 & 0 & 0 & 0 & $\begin{array}{l}\left(B_{16}-B_{15}\right) \\
\alpha_{4}\end{array}$ & 0 & $\left(B_{16}-B_{15}\right) \cdot \alpha_{6}$ & 0 & 0 & 0 & $\mathrm{~B}_{16}-\mathrm{B}_{15}$ \\
\hline $\mathrm{P}_{9}$ & 0 & 0 & 0 & 0 & 0 & $\mathrm{~B}_{19}-\mathrm{B}_{18}$ & & 0 & 0 & 0 & $\mathrm{~B}_{19}-\mathrm{B}_{18}$ \\
\hline $\begin{array}{l}\text { Tot } \\
\text { fuel }\end{array}$ & $\mathrm{B}_{3}+\mathrm{B}_{25}+\mathrm{B}_{26}$ & $\mathrm{~B}_{1}+\mathrm{B}_{2}$ & $\mathrm{~B}_{4}-\mathrm{B}_{5}$ & $\mathrm{~B}_{8}-\mathrm{B}_{9}$ & $\mathrm{~B}_{14}-\mathrm{B}_{15}$ & $\mathrm{~B}_{17}-\mathrm{B}_{18}$ & $\mathrm{~B}_{23}+\mathrm{B}_{24}+\mathrm{B}_{13}-\mathrm{B}_{14}$ & $\mathrm{~B}_{20}$ & $\mathrm{~B}_{21}$ & $\mathrm{~B}_{22}$ & \\
\hline
\end{tabular}

Table 6

Thermoecological cost of selected fuels.

\begin{tabular}{lll}
\hline No. & Fuel & $\mathrm{TEC}^{*}\left(r_{e}\right), \mathrm{MJ}^{*} / \mathrm{MJ}_{\mathrm{ex}}$ \\
\hline 1. & Methane from coal mine & $\mathbf{0 . 2 2 0}$ \\
2. & Domestic natural gas (without $\mathrm{CH}_{4}$ emission) & 1.004 \\
3. & Domestic natural gas (with $\mathbf{C H}_{4}$ emissions) & $\mathbf{1 . 0 8 2}$ \\
4. & Imported (Siberian) natural gas (without $\mathrm{CH}_{4}$ emission) & 1.374 \\
5. & Imported (Siberian) natural gas (with $\mathrm{CH}_{4}$ emission) & 1.522 \\
6. & Polish natural gas mix (30\% domestic $+70 \%$ imported; without $\mathrm{CH}_{4}$ emission) & 1.263 \\
7. & Polish natural gas mix (30\% domestic $+\mathbf{7 0 \%}$ imported; with $\mathbf{C H}_{4}$ emission) & $\mathbf{1 . 3 9 0}$ \\
8. & Methanol produced from biomass & 0.328 \\
$\mathbf{9 .}$ & SNG (syngas) produced from biomass & $\mathbf{0 . 1 3 5}$ \\
\hline
\end{tabular}

Table 7

Formation of unit TEC of the products of the plant components $\left(\mathrm{r}_{\mathrm{P}}\right)$, for the example of coal mine methane.

\begin{tabular}{|c|c|c|c|c|c|c|c|c|c|c|}
\hline 1MMC & Component & 1. ICE & 2. HRHE & 3. PSHE & 4. $\mathrm{HC}$ & 5. CC & 6. AC & 7. PP & 8. PS & 9. PCC \\
\hline Total $r_{P}$ & & 0.9082 & 2.6503 & 1.8850 & 1.8751 & 10.354 & 9.0559 & 0.9328 & 0.9440 & 1.0963 \\
\hline \multirow[t]{14}{*}{ Formation of $r_{P}$} & IDEAL SYSTEM & 0.2200 & 0.2200 & 0.2200 & 0.2200 & 0.2200 & 0.2200 & 0.2200 & 0.2200 & 0.2200 \\
\hline & I 1. ICE & 0.1961 & 0.5724 & 0.4071 & 0.4050 & 2.2363 & 1.9559 & 0.2015 & 0.2039 & 0.2368 \\
\hline & I 2. HRHE & 0 & 0.4220 & 0.2163 & 0.2131 & 1.1217 & 0.9949 & 0 & 0 & 0 \\
\hline & I 3. PSHE & 0 & 0 & 0.0203 & 0.0200 & 0.1053 & 0.09334 & 0 & 0 & 0 \\
\hline & I 4. HC & 0 & 0 & 0 & 0.00092 & 0 & 0 & 0 & 0 & 0 \\
\hline & I 5. CC & 0 & 0 & 0 & 0 & 0.05696 & 0 & 0 & 0 & 0 \\
\hline & I 6. AC & 0 & 0 & 0 & 0 & 0.9970 & 0.8843 & 0 & 0 & 0 \\
\hline & I 7. PP & 0 & 0 & 0.00005 & 0.00005 & 0.00026 & 0.00023 & 0.00596 & 0 & 0 \\
\hline & I 8. PS & 0 & 0 & 0 & 0.00016 & 0.00086 & 0.00076 & 0 & 0.00866 & 0 \\
\hline & I 9. PCC & 0 & 0 & 0 & 0 & 0.00599 & 0 & 0 & 0 & 0.0456 \\
\hline & $\mathrm{EM} \mathrm{SO}_{2}$ & 0 & 0 & 0 & 0 & 0 & 0 & 0 & 0 & 0 \\
\hline & $\mathrm{EM} \mathrm{NO}_{\mathrm{X}}$ & 0.0315 & 0.0920 & 0.0654 & 0.0651 & 0.3594 & 0.3144 & 0.0324 & 0.0328 & 0.0381 \\
\hline & $\mathrm{EM} \mathrm{CO} 2$ & 0.4529 & 1.3216 & 0.9400 & 0.9351 & 5.1632 & 4.5159 & 0.4652 & 0.4707 & 0.5467 \\
\hline & EM CO & 0.00763 & 0.0223 & 0.0158 & 0.0158 & 0.0870 & 0.0761 & 0.00784 & 0.00793 & 0.00921 \\
\hline
\end{tabular}

Table 8

Formation of unit TEC of the products of the plant components $\left(\mathrm{r}_{\mathrm{P}}\right)$, for the example of domestic natural gas with methane emission.

\begin{tabular}{|c|c|c|c|c|c|c|c|c|c|c|}
\hline 3domNG & Component & 1. ICE & 2. HRHE & 3. PSHE & 4. $\mathrm{HC}$ & 5. CC & 6. AC & 7. PP & 8. PS & 9. PCC \\
\hline Total $r_{P}$ & & 2.5241 & 7.3833 & 5.2477 & 5.2200 & 28.821 & 25.209 & 2.5924 & 2.6235 & 3.0470 \\
\hline \multirow[t]{14}{*}{ Formation of $r_{P}$} & IDEAL SYSTEM & 1.0820 & 1.0820 & 1.0820 & 1.0820 & 1.0820 & 1.0820 & 1.0820 & 1.0820 & 1.0820 \\
\hline & I 1. ICE & 0.9639 & 2.8195 & 2.0040 & 1.9934 & 11.0062 & 9.6266 & 0.9900 & 1.0018 & 1.1636 \\
\hline & I 2. HRHE & 0 & 2.0830 & 1.0675 & 1.0518 & 5.5364 & 4.9107 & 0 & 0 & 0 \\
\hline & I 3. PSHE & 0 & 0 & 0.0998 & 0.0983 & 0.5177 & 0.4591 & 0 & 0 & 0 \\
\hline & I 4. HC & 0 & 0 & 0 & 0.00452 & 0 & 0 & 0 & 0 & 0 \\
\hline & I 5. CC & 0 & 0 & 0 & 0 & 0.2801 & 0 & 0 & 0 & 0 \\
\hline & I 6. AC & 0 & 0 & 0 & 0 & 4.9035 & 4.3493 & 0 & 0 & 0 \\
\hline & I 7. PP & 0 & 0 & 0.00024 & 0.00024 & 0.00126 & 0.00112 & 0.0293 & 0 & 0 \\
\hline & I 8. PS & 0 & 0 & 0 & 0.00080 & 0.00424 & 0.0376 & 0 & 0.0426 & 0 \\
\hline & I 9. PCC & 0 & 0 & 0 & 0 & 0.0295 & 0 & 0 & 0 & 0.2241 \\
\hline & $\mathrm{EM} \mathrm{SO}_{2}$ & 0.00114 & 0.00333 & 0.00236 & 0.00235 & 0.0130 & 0.0114 & 0.00117 & 0.00118 & 0.00137 \\
\hline & EM NO & 0.0317 & 0.0927 & 0.0659 & 0.0655 & 0.3619 & 0.3165 & 0.0326 & 0.0329 & 0.0383 \\
\hline & $\mathrm{EM} \mathrm{CO} 2$ & 0.4377 & 1.280 & 0.9100 & 0.9052 & 4.9977 & 4.3713 & 0.4495 & 0.4549 & 0.5284 \\
\hline & EM CO & 0.00767 & 0.0224 & 0.0160 & 0.0159 & 0.0876 & 0.0766 & 0.00788 & 0.00798 & 0.00926 \\
\hline
\end{tabular}


Table 9

Formation of unit TEC of the products of the plant components $\left(r_{p}\right)$, for the Polish natural gas mix with methane emission.

\begin{tabular}{|c|c|c|c|c|c|c|c|c|c|c|}
\hline $7 \mathrm{P} \operatorname{mix} \mathrm{NG}$ & Component & 1. ICE & 2. HRHE & 3. PSHE & 4. HC & 5. CC & 6. AC & 7. PP & 8. PS & 9. PCC \\
\hline Total $r_{P}$ & & 3.1065 & 9.0868 & 6.4585 & 6.4245 & 35.471 & 31.025 & 3.1906 & 3.2288 & 3.7500 \\
\hline \multirow[t]{14}{*}{ Formation of $r_{p}$} & IDEAL SYSTEM & 1.3900 & 1.3900 & 1.3900 & 1.3900 & 1.3900 & 1.3900 & 1.3900 & 1.3900 & 1.3900 \\
\hline & I 1. ICE & 1.1383 & 3.6221 & 2.5744 & 2.5609 & 14.1392 & 12.3669 & 1.2718 & 1.2871 & 1.4948 \\
\hline & I 2. HRHE & 0 & 2.6759 & 1.3713 & 1.3511 & 7.1124 & 6.3086 & 0 & 0 & 0 \\
\hline & I 3. PSHE & 0 & 0 & 0.1282 & 0.1263 & 0.6650 & 0.5899 & 0 & 0 & 0 \\
\hline & I 4. HC & 0 & 0 & 0 & 0.00581 & 0 & 0 & 0 & 0 & 0 \\
\hline & I 5. CC & 0 & 0 & 0 & 0 & 0.03599 & 0 & 0 & 0 & 0 \\
\hline & I 6. AC & 0 & 0 & 0 & 0 & 6.2993 & 5.5874 & 0 & 0 & 0 \\
\hline & I 7. PP & 0 & 0 & 0.00031 & 0.00031 & 0.00162 & 0.00143 & 0.0376 & 0 & 0 \\
\hline & I 8. PS & 0 & 0 & 0 & 0.00103 & 0.00544 & 0.00482 & 0 & 0.0547 & 0 \\
\hline & I 9. PCC & 0 & 0 & 0 & 0 & 0.0379 & 0 & 0 & 0 & 0.2879 \\
\hline & $\mathrm{EM} \mathrm{SO}_{2}$ & 0.00114 & 0.00336 & 0.00236 & 0.00235 & 0.0130 & 0.0114 & 0.00117 & 0.00118 & 0.00137 \\
\hline & EM NO & 0.0317 & 0.0927 & 0.0659 & 0.0655 & 0.3619 & 0.3165 & 0.0326 & 0.0329 & 0.0383 \\
\hline & $\mathrm{EM} \mathrm{CO} 2$ & 0.4377 & 1.2803 & 0.9100 & 0.9052 & 4.9977 & 4.3713 & 0.4495 & 0.4549 & 0.5284 \\
\hline & EM CO & 0.00767 & 0.0224 & 0.0160 & 0.0159 & 0.0876 & 0.0766 & 0.00788 & 0.00798 & 0.00926 \\
\hline
\end{tabular}

Table 10

Formation of unit TEC of the products of the plant components $\left(r_{\mathrm{P}}\right)$, for the example of biomass syngas.

\begin{tabular}{|c|c|c|c|c|c|c|c|c|c|c|}
\hline 9 SNG bio & Component & 1. ICE & 2. HRHE & 3. PSHE & 4. $\mathrm{HC}$ & 5. CC & 6. AC & 7. PP & 8. PS & 9. PCC \\
\hline \multirow{15}{*}{$\begin{array}{l}\text { Total } r_{P} \\
\text { Formation } \\
\text { of } r_{P}\end{array}$} & & 0.2956 & 0.8633 & 0.6139 & 0.6107 & 3.3719 & 2.9492 & 0.3036 & 0.3073 & 0.3569 \\
\hline & IDEAL SYSTEM & 0.1350 & 0.1350 & 0.1350 & 0.1350 & 0.1350 & 0.1350 & 0.1350 & 0.1350 & 0.1350 \\
\hline & I 1. ICE & 0.1203 & 0.3514 & 0.2499 & 0.2486 & 1.3726 & 1.2005 & 0.1236 & 0.1251 & 0.1453 \\
\hline & I 2. HRHE & 0 & 0.2592 & 0.1329 & 0.1309 & 0.6891 & 0.6112 & 0 & 0 & 0 \\
\hline & I 3. PSHE & 0 & 0 & 0.0125 & 0.0123 & 0.0646 & 0.0573 & 0 & 0 & 0 \\
\hline & I 4. HC & 0 & 0 & 0 & 0.00056 & 0 & 0 & 0 & 0 & 0 \\
\hline & I 5. CC & 0 & 0 & 0 & 0 & 0.0350 & 0 & 0 & 0 & 0 \\
\hline & I 6. AC & 0 & 0 & 0 & 0 & 0.6118 & 0.5427 & 0 & 0 & 0 \\
\hline & I 7. PP & 0 & 0 & 0.00003 & 0.00003 & 0.00016 & 0.00015 & 0.00366 & 0 & 0 \\
\hline & I 8. PS & 0 & 0 & 0 & 0.00010 & 0.00053 & 0.00047 & 0 & 0.00532 & 0 \\
\hline & I 9. PCC & 0 & 0 & 0 & 0 & 0.00368 & 0 & 0 & 0 & 0.00280 \\
\hline & $\mathrm{EM} \mathrm{SO}_{2}$ & 0.00113 & 0.00330 & 0.00235 & 0.00234 & 0.0129 & 0.0113 & 0.00116 & 0.00118 & 0.00137 \\
\hline & $E M N_{X}$ & 0.0315 & 0.0921 & 0.0655 & 0.0651 & 0.3597 & 0.3147 & 0.0324 & 0.0328 & 0.0381 \\
\hline & $\mathrm{EM} \mathrm{CO} 2$ & 0 & 0 & 0 & 0 & 0 & 0 & 0 & 0 & 0 \\
\hline & EM CO & 0.00763 & 0.0223 & 0.0158 & 0.0158 & 0.0870 & 0.0761 & 0.00784 & 0.00793 & 0.00921 \\
\hline
\end{tabular}

corresponding to biomass growing, harvesting and processing (outside the analysed system) are included in the TEC of biomass.

\section{Conclusions}

The presented study shows that the 'sustainability footprint' (expressed by the thermoecological cost) of energy carriers produced in a trigeneration system depends mainly on two factors:

- type of final energy carrier (electricity/heat/cooling agent)

- type of fuel supplied to the system

Observing the TEC of final products generated for a given type of fuel, one can note that electricity has the lowest cost, the cost of heat is about twice higher, while the cost of the cooling agent is higher by an order of magnitude. This fact results not only from different quality of electricity, heat and cooling effect measured by their exergy, but mainly from the different formation process (involving components with different efficiencies). In particular, exergy of the cooling agent is very low if it is supplied at a level close to the environment temperature, which causes high cost of that flow.

The effect of different fuel is expressed by the TEC of fluxes entering the considered system. It was shown that 'side effects' constitute an important part of the TEC, e.g. the TEC of natural gas is higher than unity and may reach 1.5 , while the TEC of renewable fuels is nonzero (about 0.14 for the analysed syngas). An interesting effect is observed for the case of coal mine methane (CMM), which is a non-renewable resource. However, provided that coal extraction occurs anyway, the acquisition of CMM allows one to avoid direct (uncombusted) methane emission, which lowers the TEC of CMM to the value of about 0.22 for the analysed coal bassin.

The proposed methodology quantifies in detail how TEC propagates along the system due to irreversibility in different components and also due to emissions. TEC of the product of each component is affected not only by that component but also by components located upstream. For instance, heat exchanger 5 is located at the end of the production chain and, thus, has a high product cost. Besides, the effect of pollutants is also identified; examples such as $\mathrm{CO}_{2}$ for $\mathrm{CMM}$ show that this effect is not always negligible. With all this information, components with higher impact on TEC are clearly identified, which is a key step for system efficiency improvement.

High exergy cost of the generated cooling effect entails a general message: currently, air-conditioning and refrigeration technologies are primarily based on the combustion of fuels, also including non-renewables. However, achieving a moderate chilling effect is frequently possible by alternative, sustainable strategies, like: using ambient air (ventillation/windows), using natural draught cooling, storing products in underground cellars, using evaporative cooling techniques, appropriate design of buildings to manage the access of sunlight/shadow. Many of these techniques have been used by previous generations and should be seriously reconsidered.

It should be stressed that the objective of the paper is not to provide particular recommendations on the system, which is treated as an example. On the contrary, the aim of this work is to demonstrate how the thermoecological cost (and, in particular, its 
calculation from the joint TEA-TEC methodology developed in the paper) can be used as a sustainability indicator, as it accounts for key environmental issues (depletion of resources and the generation of harmful substances) in a cumulative perspective.

\section{Acknowledgements}

The support from the statutory research fund of the Faculty of Power and Environmental Engineering of SUT, Gliwice, Poland is gratefully acknowledged.

\section{Nomenclature}

$a_{i j} \quad$ flux of $i$-th input material per unit product, $(\mathrm{kg}$ or $\mathrm{kJ}) /(\mathrm{kg}$ or $\mathrm{kJ}$ ) (Bold letters denote the corresponding vectors, e.g $\mathbf{F}$ is the vector of fuel for all components.)

$b \quad$ specific exergy, $\mathrm{kJ} / \mathrm{kg}$

$\dot{B} \quad$ exergy flux, $\mathrm{kW}$

$E \quad$ exergy flux (in a productive structure), $\mathrm{kW}$

$E^{*} \quad$ exergy cost (in a productive structure), $\mathrm{kW}$

EM $^{*}$ TEC thermoecological cost of emissions, $\mathrm{kW}$

$F \quad$ fuel, kW

$<$ FP $>\quad$ matrix of distribution coefficients

$h \quad$ specific enthalpy, $\mathrm{kJ} / \mathrm{kg}$

I irreversibility, $\mathrm{kW}$

$k^{*} \quad$ unit exergy cost

$\dot{m} \quad$ mass flow rate, $\mathrm{kg} / \mathrm{s}$

$p \quad$ pressure, $\mathrm{kPa}$

$p_{k j} \quad$ flux of k-th harmful substance per unit product, $\mathrm{kg} /(\mathrm{kg}$ or $\mathrm{kJ})$

$P \quad$ product, $\mathrm{kW}$

$P^{*} \quad$ product cost, $\mathrm{kW}$

$r \quad$ thermoecological cost (specific)

$T$ temperature, ${ }^{\circ} \mathrm{C}$

$\mathbf{U}_{\mathbf{D}} \quad$ identity matrix

$\dot{V}_{n} \quad$ volumetric flux normalized at $0{ }^{\circ} \mathrm{C}, 101.325 \mathrm{kPa}, \mathrm{m}^{3} / \mathrm{s}$

$y \quad$ distribution coefficient

\section{Greek symbols}

$\beta_{s j} \quad$ consumption of the s-th direct resource per unit product, $\mathrm{kJ} /(\mathrm{kg}$ or $\mathrm{kJ})$

$\mu \quad$ degree of utilization of $\mathrm{CMM}$

$\zeta \quad$ cost of compensation, $\mathrm{kJ} / \mathrm{kg}$

\section{Subscripts, superscripts}

e eternal resources

i current or upstream component

j current or downstream component

$\mathrm{P} \quad$ product

S system

0 environment

* based on exergy cost

*TEC thermoecological cost (in a productive structure)

\section{Acronyms}

CMM coal mine methane

ICE internal combustion engine

LHV lower heating value, $\mathrm{kJ} / \mathrm{m}^{3} \mathrm{n}$

NG natural gas

TEC thermoecological cost (generic, per any unit of measure)

SNG

\section{References}

[1] Hall RE, Taylor JB. Macroeconomics. New York: W. W. Norton and Company; 1997.

[2] Rogall H. Nachhaltige Ökonomie. Ökonomische Theorie und Praxix einer Nachhaltigen Entwicklung. Marburg: Metropolis-Verlag; 2009. Polish translation: Ekonomia zrównoważonego rozwoju, Zysk Press. Psoznań Poland 2010.

[3] BP statistical review of world energy. www.bp.com [last accessed - April 2014].

[4] Wang JJ, Jing YY, Zhang CF, Zhai Z. Performance comparison of combined cooling heating and power system in different operation modes. Appl Energy 2011;88:4621-31.

[5] Chicco G, Mancarella P. Trigeneration primary energy saving evaluation for energy planning and policy development. Energy Policy 2007;35:6132-44.

[6] Wang JJ, Jing YY, Zhang CF, Zhai Z. Performance comparison of combined cooling heating and power system in different operation modes. Appl Energy 2011:88:4621-31.

[7] Fumo N, Chamra LM. Analysis of combined cooling, heating, and power systems based on source primary energy consumption. Appl Energy 2010;87: 2023-30.

[8] Stanek W, Gazda W. Exergo-ecological evaluation of adsorption chiller system. Energy 2014. http://dx.doi.org/10.1016/j.energy.2014.02.053.

[9] Mateus T, Oliveira AC. Energy and economic analysis of an integrated solar absorption cooling and heating system in different building types and climates. Appl Energy 2009;86:949-57.

[10] Onan C, Ozkan DB, Erdem S. Exergy analysis of a solar assisted absorption cooling system on an hourly basis in villa applications. Energy 2010;35: 5277-85.

[11] Padilla RV, Demirkaya G, Goswami DY, Stefanakos E, Rahman MM. Analysis of power and cooling cogeneration using ammonia-water mixture. Energy 2010;35:4649-57.

[12] Khaliq A, Dincer I. Energetic and exergetic performance analyses of a combined heat and power plant with absorption inlet cooling and evaporative aftercooling. Energy 2011;36:2662-70.

[13] Salehzadeh A, Khoshbakhti Saray R, JalaliVahid D. Investigating the effect of several thermodynamic parameters on exergy destruction in components of a trigeneration cycle. Energy 2013;52:96-109.

[14] Chekir N, Bellagi A. Performance improvement of a butane/octane absorption chiller. Energy 2011;36:6278-84.

[15] Kim YJ, Kim S, Joshi YK, Fedorov AG, Kohl PA. Thermodynamic analysis of an absorption refrigeration system with ionic-liquid/refrigerant mixture as a working fluid. Energy 2014;44:1005-16.

[16] Farshi LG, Mahmoudi SMS, Rosen MA. Exergoeconomic comparison of double effect and combined ejector-double effect absorption refrigeration systems. Appl Energy 2013;103:700-11.

[17] Liua M, Zhanga Na. proposal and analysis of a novel ammonia-water cycle for power and refrigeration cogeneration. Energy 2007;32:961-70.

[18] Handbook ASHRAE. Refrigeration. Atlanta: American Society of Heating, Refrigerating and Air-Conditioning Engineers Inc.; 2010.

[19] Kilic M, Kaynakli O. Second law-based thermodynamic analysis of waterlithium bromide absorption refrigeration system. Energy 2007;32: $1505-12$.

[20] Valero A, Lozano M, Muñoz M. A general theory of exergy saving. Part I: on the exergetic cost. In: Gaggioli R, editor. Computer aided engineering and energy systems. Second law analysis and modeling, vol. 3. New York, USA: ASME; 1986. p. $1-8$

[21] Usón S, Valero A, Agudelo A. Thermoeconomics and industrial symbiosis. Effect of by-product integration in cost assessment. Energy 2012;35:43-51.

[22] Valero A, Usón S, Torres C, Al Valero, Agudelo A, Costa J. Thermoeconomic tools for the analysis of eco-industrial parks. Energy 2013;62:62-72.

[23] Valero A. Exergy accounting: capabilities and drawbacks. Energy 2006;31: $164-80$.

[24] Szargut J. Analysis of cumulative exergy consumption. Energy Res 1987;4: $541-7$.

[25] Szargut J, Ziębik A, Stanek W. Depletion of the non-renewable natural exergy resources as a measure of the ecological cost. Energy Convers Manage 2002;42:1149-63.

[26] Szargut J. Exergy method: technical and ecological applications. Southampton, UK: WIT-Press; 2005.

[27] Stanek W. Method of evaluation of ecological effects in thermal processes with the application of exergy analysis. Silesian University of Technology Press; 2009 [in Polish].

[28] Stanek W, Gazda W, Kostowski W. Thermo-ecological assessment of CCHP (combined cold-heat-and-power) plant supported with renewable energy. Energy 2015;92:279-89. http://dx.doi.org/10.1016/j.energy.2015.02.005.

[29] Kostowski W, Usón S, Stanek W, Bargiel P. Thermoecological cost of electricity production in the natural gas pressure reduction process. Energy 2014;76(1): 10-8. http://dx.doi.org/10.1016/j.energy.2014.01.045. Available online 8 February 2014.

[30] Stanek W. Examples of application of exegy analysis for the evaluation of ecological effects in thermal processes. Int J Thermodyn 2012;15(1).

[31] Stanek W, Czarnowska L. Environmental externalities and its influence on the thermoecological cost. Int J Sustain Water Environ Syst 2012;4(1):51-8. 
[32] Valero A, Torres C. Thermoeconomic analysis. Oxford UK: EOLSS Publishers; 2006 [accessed Dec 2013], www.eolss.net.

[33] Tsatsaronis G, Winhold M. Exergoeconomic analysis and evaluation of energy conversion plants - I. A new general methodology. Energy 1985;10:69-80.

[34] Frangopoulos CA. Thermoeconomic functional analysis and optimization. Energy 1986:7:563-71.

[35] Valero A, Lozano MA, Serra L, Tsatsaronis G, Pisa J, Frangopoulos CA, et al. CGAM problem: definition and conventional solution. Energy 1994;19(3): 279-86.

[36] Tribus M, Evans RB. A contribution to the theory of thermoeconomics. Los Angeles, CA, USA: Department of Engineering, UCLA; 1962. Technical report, Report No. 62-63.

[37] Torres C. Symbolic thermoeconomic analysis of energy systems. Oxford, UK: EOLSS Publishers; 2006 [accessed Dec 2013], www.eolss.net.
[38] Natural gas distribution network operator. http://www.zabrze.psgaz.pl/ [accessed April 2014, in Polish].

[39] Jurašćík M, Sues A, Ptasinski KJ. Exergetic evaluation and improvement of biomass-to-synthetic natural gas conversion. Energy Environ Sci 2009;2(7): 791-801.

[40] Gatnar K. Production of CMM in the JSW coal company. In: Proceedings of the 5th Scientific-Technical Conference 'Gas Energy' organized by ITT/Silesian UT, Zawiercie, Poland; Oct 2013. p. 9-11 [in Polish].

[41] http://www.horus-energia.pl/dokumenty/form/2-762-13.pdf [accessed April 2014, in Polish].

[42] http://www.ebara.com.sg/images/stories/pdf/rch.pdf [accessed April 2014, in Polish]. 